\title{
Heavy Metal Contamination of Groundwater in the Tea Garden Belt of Darrang District, Assam, India
}

\author{
${ }^{*}$ K. K. BORAH, B. BHUYAN ${ }^{\S}$ and H. P. SARMA \\ *Department of Chemistry, Mangaldai College, Darrang, Assam-784 125, India. \\ ${ }^{\S}$ Department of Chemistry, North Lakhimpur College, Lakhimpur-787 031, India. \\ Department of Environmental Science, Gauhati University, Assam-781 014, India. \\ bhabajitb@rediffmail.com
}

Received 1 April 2009; Accepted 5 June 2009

\begin{abstract}
A study has been carried out on heavy metal contamination of groundwater with respect to cadmium, manganese, zinc and copper in the tea garden belt of Darrang district, Assam, India. Heavy metals in groundwater are estimated by using Atomic Absorption Spectrometer, Perkin Elmer AA 200. Univariate statistics along with skewness, kurtosis and ' $t$ ' test have been employed to test the distribution normality for each metal. The study reveals that the groundwater of the area is highly contaminated with cadmium. A good number of samples are also found to contain manganese at an alert level. The concentrations of copper and zinc in the groundwater of the area are within the guideline values of WHO. Statistical results show that all the metals under study exhibit an asymmetric distribution in the area with a long asymmetric tail on the right of the median. Keeping in view of the high concentrations of cadmium and manganese, it is suggested to test the potability of groundwater of the area before using it for drinking.
\end{abstract}

Keywords: Cadmium, Manganese, Skewness, Kurtosis and t-Test.

\section{Introduction}

Heavy metal contamination of groundwater more often than not goes unnoticed and remains hidden from the public view. Presently, it has raised wide spread concerns in different parts of the world and results reported by various agencies have been alarming ${ }^{1-2}$. There is also evidence of prevailing heavy metal contamination of groundwater in many areas of India ${ }^{3-5}$. Cadmium is today regarded as the most serious contaminant of the modern age. Copper is classified as a priority pollutant because of its adverse health effects. Manganese is most often a concern for systems that use a groundwater source. Zinc is an essential element and is generally considered to be non-toxic below $5.0 \mathrm{mg} / \mathrm{L}$. Thus, the monitoring of groundwater 
quality has been universally recognized as the quality of ground water cannot be restored once it is contaminated, by stopping the flow of pollutants from the source. The elevated metal level in groundwater is a new public concern in Assam. But unfortunately, very few data on heavy metal contamination of groundwater are available in Assam. The need is for a more systematic and careful study eliminating all possible sources of error and to build up a reliable database. Groundwater ccontamination of metals with respect to cadmium, manganese, zinc and copper in the tea garden belt of Darrang district, Assam has been presented in this study.

\section{Profile of the study area}

The study area Darrang district is situated in the eastern parts of India on the northeast corner of Assam. Located on the bank of mighty river Brahmaputra, the district is largely plain. The district lies between $26^{\circ} 25^{\prime}$ and $26^{\circ} 55^{\prime}$ northern latitude and $91^{\circ} 45^{\prime}$ and $91^{\circ} 20^{\prime}$ eastern longitude Figure 1.

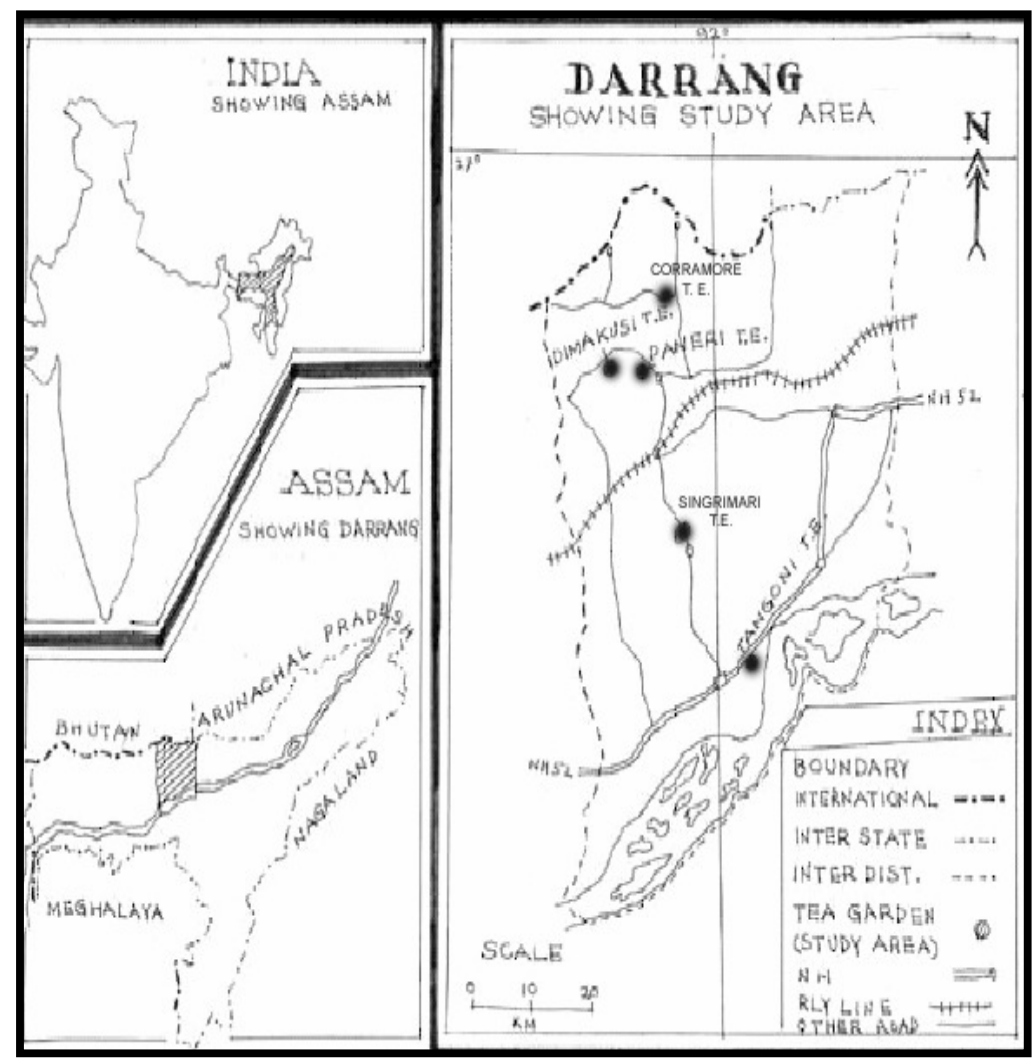

Figure 1. Sketch map of Darrang district showing its location.

\section{Sampling information}

For the present study, twenty eight water samples were collected inside as well as outside five tea gardens of Darrang district during June to November, 2008 (Table 1). 
Table 1. Water sampling locations and sources.

\begin{tabular}{|c|c|c|c|c|c|}
\hline S. No. & Sampling stations & Source & S. No. & Sampling stations & Source \\
\hline A1 & Inside Tangoni Tea Garden & Tubewell & I B1 & Outside Tangoni Tea Garden & Tubewell \\
\hline A2 & Inside Tangoni Tea Garden & Tubewell & I B2 & Outside Tangoni Tea Garden & Tubewell \\
\hline A3 & Inside Tangoni Tea Garden & Tubewell & B B & Outside Paneri Tea Garden & Tubewell \\
\hline A4 & Inside Paneri Tea Garden & Tubewell & B4 & Outside Paneri Tea Garden & Ringwell \\
\hline A5 & Inside Paneri Tea Garden & Tubewell & B5 & Outside Dimakusi Tea Garden & Tubewell \\
\hline A6 & Inside Paneri Tea Garden & Tubewell & B6 & Outside Dimakusi Tea Garden & Tubewell \\
\hline A7 & Inside Dimakusi Tea Garden & Tubewell & B7 & $\begin{array}{l}\text { Outside (Ghagrapara) } \\
\text { Corramore tea garden }\end{array}$ & Ringwll \\
\hline A8 & Inside Dimakusi tea garden & Ringwell & B8 & $\begin{array}{l}\text { Outside ( Ghagrapara ) } \\
\text { Corramore tea garden }\end{array}$ & Ringwell \\
\hline A9 & $\begin{array}{l}\text { Inside (Ghagrapara division) } \\
\text { Corramore tea garden }\end{array}$ & Ringwell & B9 & Outside Corramore Tea Garden & Ringwell \\
\hline A10 & $\begin{array}{l}\text { Inside (Ghagrapara division) } \\
\text { Corramore tea garden }\end{array}$ & Ringwell & B10 & Outside Corramore Tea Garden & Ringwell \\
\hline A11 & Inside Corramore tea garden & Stream & B1 & Outside Singrimari Tea garden & Ringwell \\
\hline A12 & Inside Corramore Tea Garden & Stream & B12 & Outside Tangoni Tea Garden & Ringwell \\
\hline A13 & Inside Singrimari Tea Garden & Tubewell & B 13 & Outside Paneri Tea Garden & Tubewell \\
\hline A14 & Inside Singrimari Tea Garden & Tubewell & B14 & Outside Dimakusi Tea garden & Ringwell \\
\hline
\end{tabular}

\section{Experimental}

Separate water samples were selected by random selection and compiled together in clean and sterile one litre polythene cans rinsed with dilute $\mathrm{HCl}$ to set a representative sample and stored in an ice box. Samples were protected from direct sun light during transportation to the laboratory and metals were analyzed as per the standard procedures ${ }^{6}$. All the metals were estimated by using Atomic Absorption Spectrometer (Perkin Elmer AA 200). The instrument was used in the limit of precised accuracy and chemicals used were of analytical grade. Doubly-distilled water was used for all purposes.

\section{Data analysis}

Univariate statistics were used to test distribution normality for each metal. The confidence interval was calculated at 0.05 level. $t$-Test is done under null hypothesis $\left(\mathrm{H}_{0}\right)$ by taking the assumption that the experimental data are consistent with the mean rating given by $\mathrm{WHO}^{7}$. Simple correlation analysis was used to relate the metal concentrations among themselves. Moment coefficients of skewness and kurtosis were calculated to express how the shapes of sample frequency distribution curves differ from ideal Gaussian (normal). Skewness was calculated as third moment of the population mean. In asymmetrical distributions, skewness can be positive or negative. Kurtosis was calculated as fourth moment of the population to describe the heaviness of the tails for a distribution. Some more statistical estimates derived from the normal distribution in the form of sample variance, $1^{\text {st }}, 2^{\text {nd }}, 3^{\text {rd }}$ Quartile, Inter Quartile Range (IQR) were also made in the present study to find out the distribution pattern of the data and other related information Details of these may be found in standard books on statistics and software packages ${ }^{8}$.

\section{Results and Discussion}

The results of analysis of various metals in groundwater samples of the tea garden belt of Darrang district, Assam are given in Table 2. To get an idea about the distribution pattern of the metal contents in groundwater inside and outside the tea gardens separately, data are graphically represented in Figure 2 and 3 respectively. To look into the trend and distribution patterns of cadmium, manganese, zinc and copper in groundwater of the study 
area, data obtained from 28 sampling stations were exposed to several statistical treatments as discussed briefly in the methodology section. A conventional descriptive statistics based on normal distribution has been shown in Table 3.

Table 2. Metal contents of groundwater in the tea garden belt of Darrang district.

\begin{tabular}{ccccc}
\hline S. No. & Cu, ppm & Mn, ppm & Cd, ppm & Zn, ppm \\
\hline A1 & 0.147 & BDL & 0.102 & 0.011 \\
A2 & 0.089 & BDL & 0.112 & 0.027 \\
A3 & 0.067 & BDL & 0.098 & 0.553 \\
A4 & 0.032 & 0.026 & 0.016 & 0.172 \\
A5 & 0.021 & 0.065 & 0.086 & 0.066 \\
A6 & 0.043 & BDL & 0.023 & 0.012 \\
A7 & 0.001 & BDL & 0.154 & 0.236 \\
A8 & 0.011 & 0.002 & BDL & 0.346 \\
A9 & 0.012 & BDL & 0.272 & 0.308 \\
A10 & 0.083 & 0.001 & 0.154 & 0.177 \\
A11 & 0.017 & BDL & 0.015 & 0.402 \\
A12 & 0.018 & BDL & BDL & 0.064 \\
A13 & 0.039 & 0.028 & 0.051 & 0.067 \\
A14 & 0.037 & 0.041 & 0.079 & 0.321 \\
B1 & 0.081 & 3.440 & BDL & 0.418 \\
B2 & 0.098 & 0.600 & BDL & 0.541 \\
B3 & 0.005 & BDL & BDL & 0.022 \\
B4 & 0.009 & BDL & 0.015 & 0.321 \\
B5 & 0.004 & BDL & 0.198 & 0.195 \\
B6 & 0.001 & 0.003 & 0.169 & 0.231 \\
B7 & 0.047 & BDL & 0.081 & 0.355 \\
B8 & 0.055 & BDL & 0.110 & 1.493 \\
B9 & 0.027 & BDL & 0.146 & 0.541 \\
B10 & 0.021 & BDL & 0.102 & 0.413 \\
B11 & 0.033 & 0.0045 & 0.001 & 0.211 \\
B12 & 0.005 & 0.107 & BDL & 0.511 \\
B13 & 0.007 & 0.085 & BDL & 0.481 \\
B14 & 0.062 & BDL & 0.093 & 0.472 \\
\hline & & $*$ & BDL & Bel Decion
\end{tabular}

"BDL: Below Detection Limit

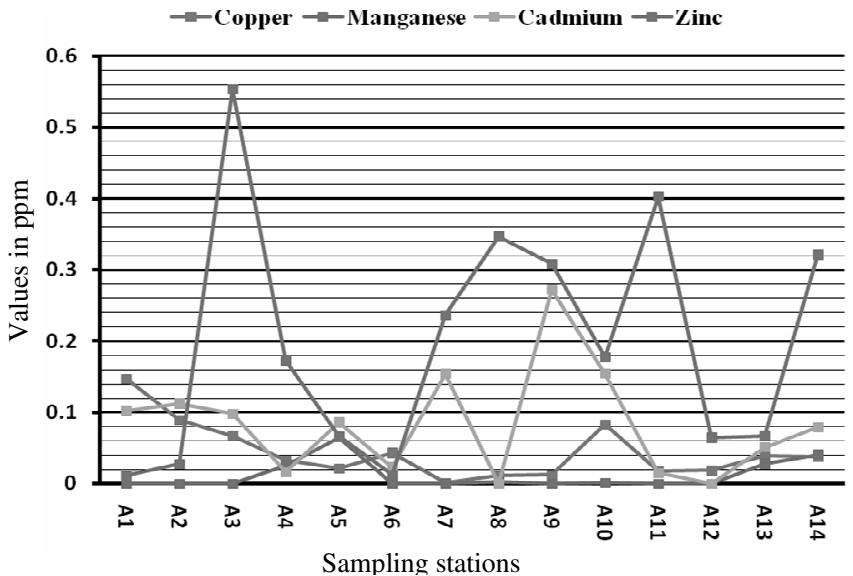

Figure 2. Variation of metal contents of groundwater inside the tea gardens. 


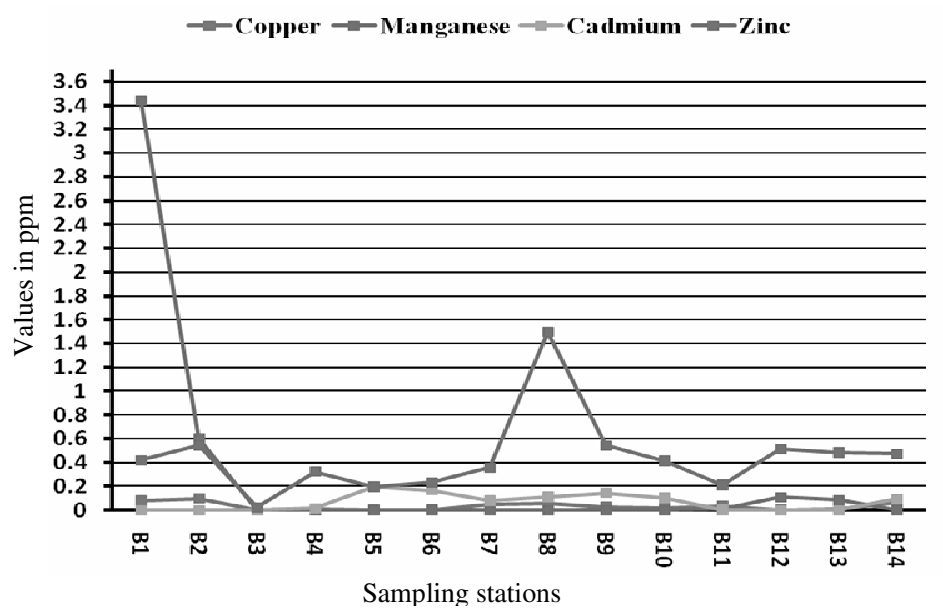

Figure 3. Variation of metal contents of groundwater outside the tea gardens.

Table 3. Descriptive statistics of the metal contents of groundwater in the study area.

\begin{tabular}{lcccc}
\hline \multicolumn{1}{c}{ Statistics } & $\mathrm{Cu}$ & $\mathrm{Mn}$ & $\mathrm{Cd}$ & $\mathrm{Zn}$ \\
\hline Mean & 0.038 & 0.157 & 0.074 & 0.320 \\
Standard Error & 0.007 & 0.123 & 0.014 & 0.055 \\
Median & 0.030 & 0.000 & 0.080 & 0.315 \\
Range & 0.150 & 3.440 & 0.270 & 1.400 \\
Standard Deviation & 0.036 & 0.653 & 0.073 & 0.291 \\
Variance & 0.001 & 0.427 & 0.005 & 0.085 \\
Skewness & 1.298 & 5.058 & 0.822 & 2.420 \\
Kurtosis & 1.648 & 26.127 & 0.277 & 9.230 \\
$1^{\text {st }}$ Quartile & 0.010 & 0.000 & 0.000 & 0.093 \\
$2^{\text {nd }}$ Quartile & 0.030 & 0.000 & 0.080 & 0.315 \\
$3^{\text {rd }}$ Quartile & 0.060 & 0.028 & 0.112 & 0.459 \\
IQR & 0.044 & 0.026 & 0.109 & 0.246 \\
WHO Rating, in ppm & 2.000 & 0.400 & 0.003 & 5.000 (US Limit) \\
t-test value & 289.774 & 1.949 & 5.154 & 85.134 \\
Comment, 0.05 level & Significant & Non significant & Significant & Significant \\
95\% CL & {$[0.024-0.052]$} & {$[0.001-0.412]$} & {$[0.046-0.103]$} & {$[0.207-0.433]$} \\
No of Samples & 28 & 28 & 28 & 28 \\
\hline
\end{tabular}

Pearson's correlation coefficient matrix is presented in Table 4 to measure the linear association among different metals under study. Since the directions of association of the measured variables are unknown in advance, two-tailed test of significance was carried out.

Table 4. Correlation table.

\begin{tabular}{ccccc}
\hline & $\mathrm{Cu}$ & $\mathrm{Mn}$ & $\mathrm{Cd}$ & $\mathrm{Zn}$ \\
\hline $\mathrm{Cu}$ & 1.0000 & & & \\
$\mathrm{Fe}$ & & & & \\
$\mathrm{Mn}$ & 0.2770 & 1.0000 & & \\
$\mathrm{Cd}$ & -0.0068 & -0.2445 & 1.0000 & \\
$\mathrm{Zn}$ & 0.0184 & 0.0925 & 0.0431 & 1.0000 \\
\hline
\end{tabular}


In most of the samples under investigation, the cadmium contents were much above the guideline value of $0.003 \mathrm{ppm}$ as set by $\mathrm{WHO}^{7}$. Cadmium above the permissible limit can potentially cause nausea, vomiting, diarrhea, muscle cramps, salivation, sensory disturbances, liver injury, convulsions, shock and renal failure along with kidney, liver, bone and blood damage from a lifetime exposure. Differences between mean and median, significant positive skewness and kurtosis value indicate that the distribution of cadmium in the study area is highly asymmetric. This is also evident from the width of the third quartile, which is much greater than the first and second quartile. The cadmium contamination of groundwater in the area should be accorded maximum attention.

Manganese at concentrations above $0.15 \mathrm{ppm}$ stains plumbing fixtures and laundry and produces undesirable taste in drinks. The WHO limit for manganese in drinking water is $0.05 \mathrm{ppm}^{7}$. It is observed that as many as seven samples under observation contain manganese either at toxic or alert level. Thus, manganese contamination of groundwater in the area needs proper attention. A broad third quartile and positive skewness in case of manganese represents a long asymmetric tail on the right of the median. Heaviness of the tail for manganese distribution in the area is evident from very high positive kurtosis value.

The permissible limit for copper in drinking water is $2.0 \mathrm{mg} / \mathrm{L}^{7}$. This was set to ensure the water tastes good and to minimize staining of laundry and plumbing fixtures. The distribution of copper in groundwater of the study area is found to be within the permissible limit of $\mathrm{WHO}^{7}$ with an average of $0.038 \mathrm{ppm}$. Asymmetric nature of copper distribution is also apparent from the normal distribution statistics with positive skewness and kurtosis values.

Although the groundwater of the study area are by and large safe with regard to zinc as may be seen from Table 2, its distribution is still not uniform in the area. Wide data range and high standard deviation in case of zinc is likely to bias the normal distribution statistic. This observation is supported by positive kurtosis and skewness value, which point towards sharp zinc distribution with a long right tail in the study area.

From the correlation of the studied metals as shown in Table 3, significant correlation was found among cadmium, copper and manganese. Cadmium shares a clear negative correlation with manganese and copper content at the 0.05 level in the area.

\section{Conclusions}

Statistical observations on $\mathrm{Cd}, \mathrm{Mn}, \mathrm{Cu}$ and $\mathrm{Zn}$ in groundwater of teagarden belt of Darrang district, Assam show that all these metals exhibit an asymmetric distribution with a long asymmetric tail on the right of the median. It is observed that the groundwater of the area is contaminated with cadmium. A sizeable number of groundwater samples contain manganese at an alert level. The concentrations of copper and zinc in the groundwater of the area are either low or moderate and within the guideline values of WHO. Keeping in view of the unusually high concentrations of the harmful metals, viz. cadmium and manganese, it is advisable to test the potability of groundwater of the area before using it for drinking.

\section{Acknowledgements}

Kamala Kanta Borah is thankful to the University Grants Commission, New Delhi and Regional Office, Guwahati for allowing Teachers Fellowship vide no. F.5-43/TF/207 (NERO) /415 dated $25^{\text {th }}$ April, 2008. 


\section{References}

1. Friberg L, Nordberg G F and Vouk V B, Ed., Handbook of the toxicology of metals, Elsevier, Amsterdam, 1986, 2, 130-184.

2. WHO/UNEP GEMS, Global fresh water quality; published on behalf of the World Health Organization/United Nations Environment Programme, Oxford, Blackwell Reference, 1989.

3. Sharma A, Sharma D K, Jangir J P and Gupta C M, Indian J Environ Protect, 1989, 9(4), 294-296.

4. Bhattacharjee S, Chakravarty S, Maity S, Dureja V and Gupta K K Chemosphere, 2005, 58, 1203-1217.

5. Bhattacharya P, Chatterjee D and Jacks G, Water Resources Development, 1997, 13, 79-92.

6. APHA (American Public Health Association), Standard method for examination of water and wastewater, New York, $20^{\text {th }}$ Ed., 1998.

7. W.H.O, Guidelines for Drinking water Quality, $3^{\text {rd }}$ Ed, World Health Organisation: Geneva, 2004.

8. Meloun M, Militky J and Forina M, Chemometrics for Analytical Chemistry, Vol. 1: PC-aided Statistical Data Analysis; Ellis Horwood Ltd: Chichester, England, 1992. 


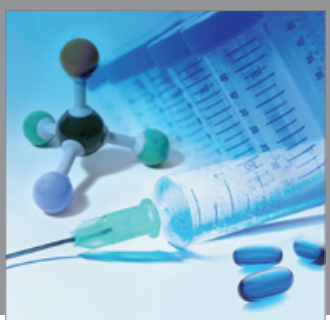

International Journal of

Medicinal Chemistry

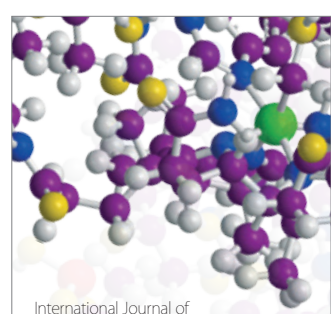

Carbohydrate Chemistry

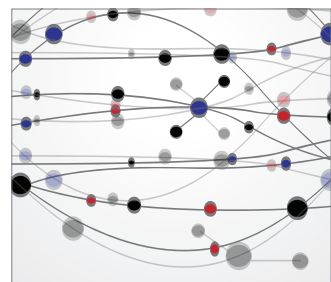

The Scientific World Journal
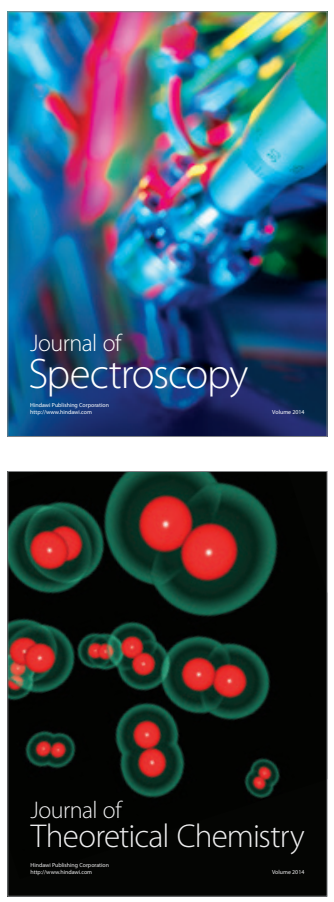
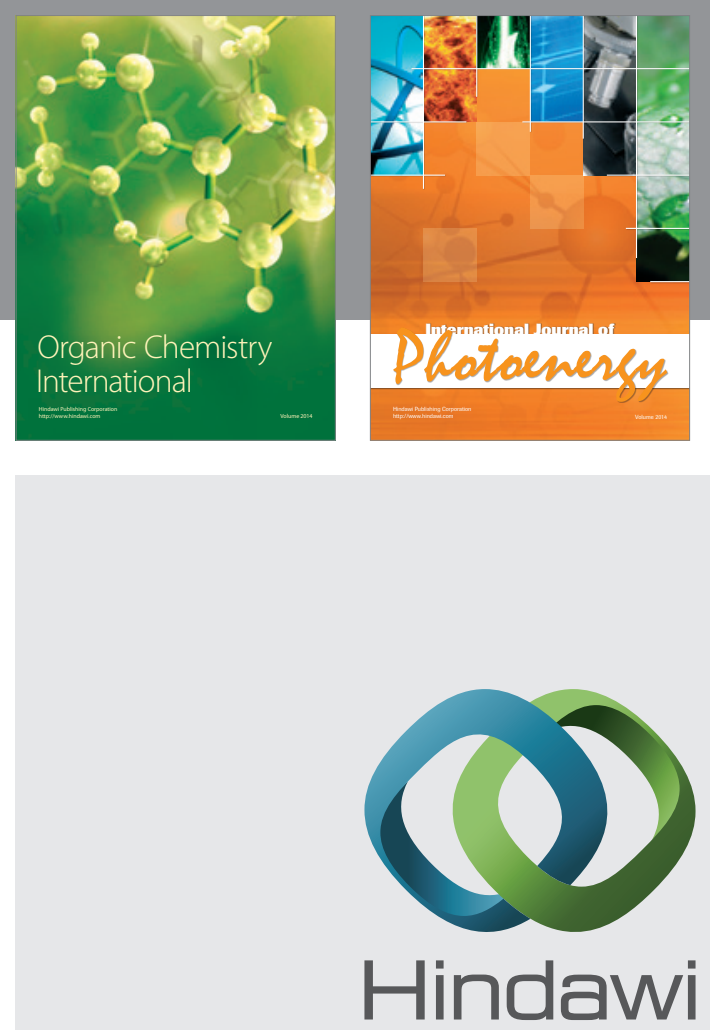

Submit your manuscripts at

http://www.hindawi.com
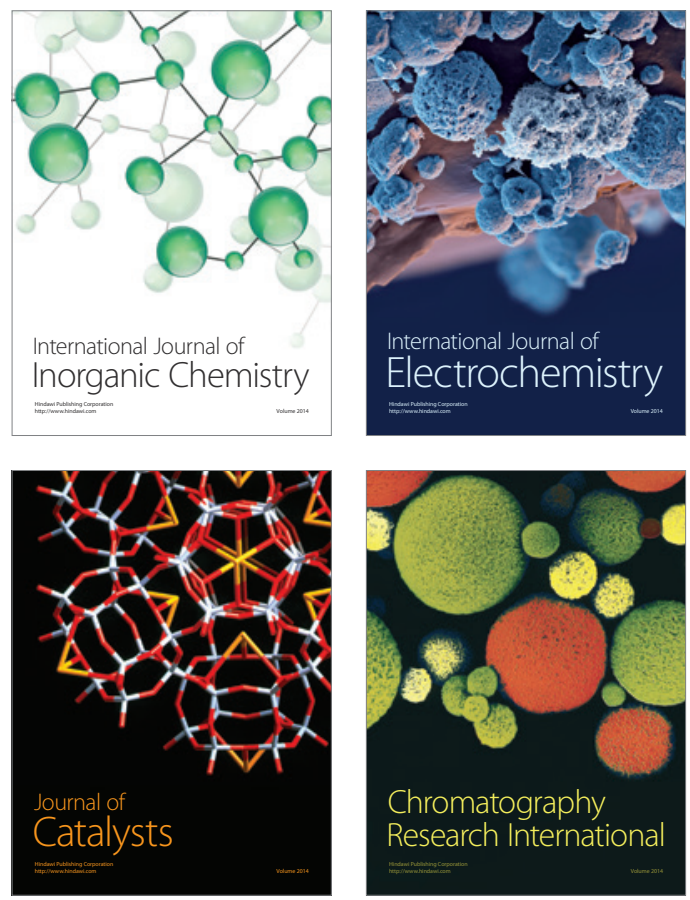
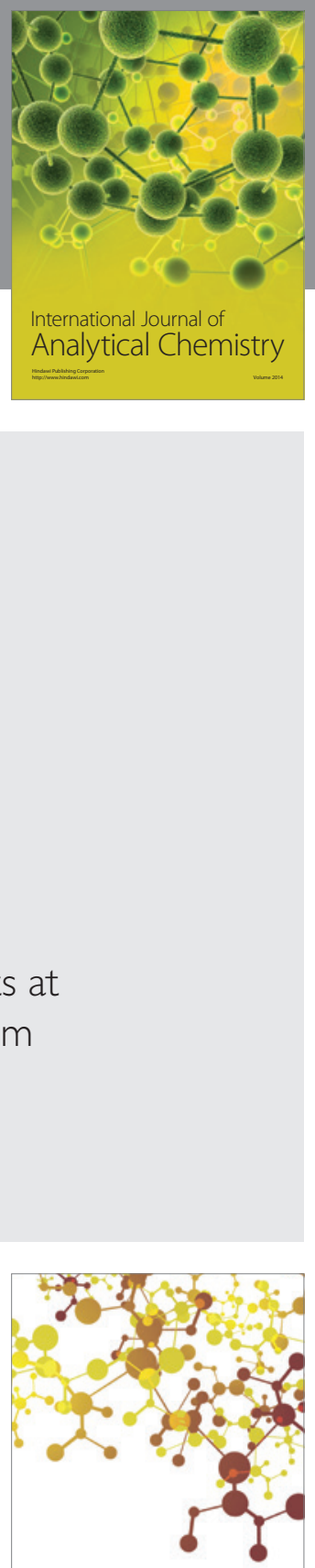

Journal of

Applied Chemistry
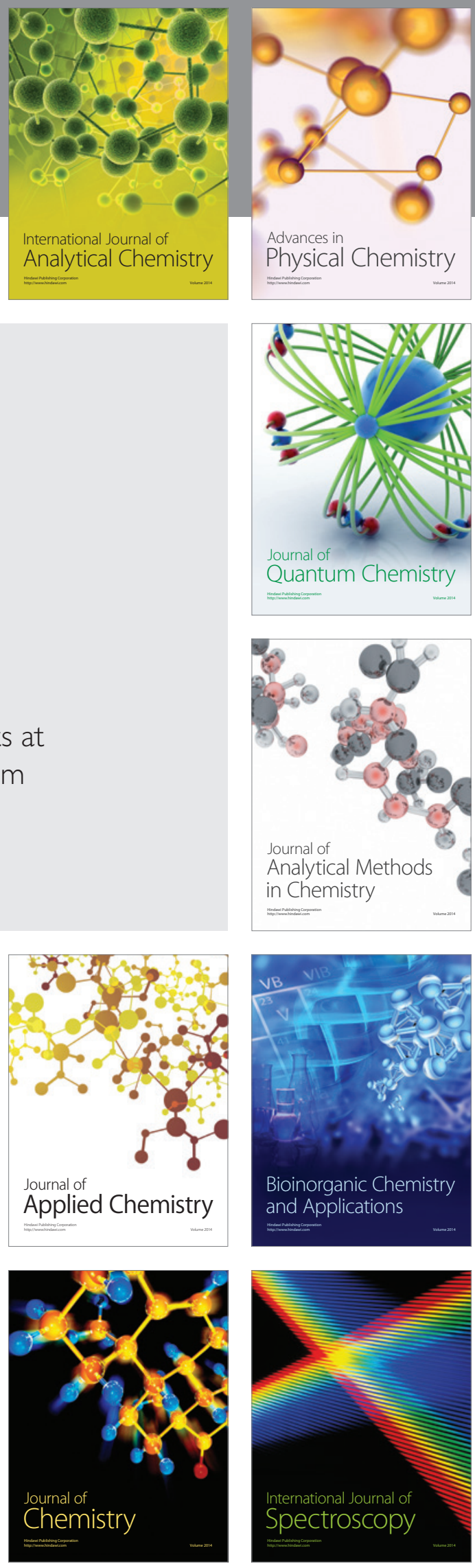